\title{
Familiarization and Reliability of the Isometric Knee Extension Test for Rapid Force Production Assessment
}

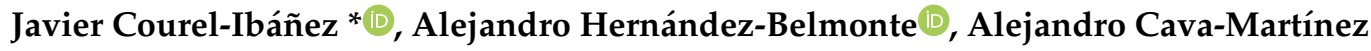 \\ and Jesús G. Pallarés \\ Faculty of Sport Sciences, Human Performance and Sports Science Laboratory, University of Murcia, \\ 30720 Murcia, Spain; alejandro.hernandez7@um.es (A.H.-B.); alejandro.mcava@gmail.com (A.C.-M.); \\ jgpallares@um.es (J.G.P.) \\ * Correspondence: courel@um.es
}

Received: 9 June 2020; Accepted: 25 June 2020; Published: 29 June 2020

Featured Application: A list of variables to inform on neuromuscular performance were easily and accurately collected using a portable force sensor and a field-based approach. Practical guidelines are provided to collect reliable rate of force development (RFD) and impulse measures of the knee extensors regarding the contraction time, preferable signal and familiarization.

\begin{abstract}
Despite the rising interest in the use of portable force sensors during isometric exercises to inform on neuromuscular performance, the design of practical field-based methods to obtain reliable measures is an ongoing challenge. We aim at identifying the intra-session and test-retest reliability of a rapid, isometric knee extension test to evaluate the maximal voluntary concentric force (MVC), rate of force development (RFD) and impulse following a field-based approach. On two occasions, 14 athletes unfamiliar with the test completed three sets of $2 \mathrm{~s}$ ballistic contractions (as fast and hard as possible) with $30 \mathrm{~s}$ rest. Raw and filtered data were collected in real time using a portable force sensor. RFD and impulse were highly reliability during "late" phases of the contraction (0-250 ms) since the first session (coefficient of variation $(\mathrm{CV})<9.8 \%$ ). Earlier phases $(0-150 \mathrm{~ms})$ achieved a moderate reliability after one familiarization session $(\mathrm{CV}<7.1 \%)$. Measures at $0-50 \mathrm{~ms}$ did not reach sufficient reliability $(\mathrm{CV} \sim 14 \%)$. MVC was accurately assessed. Dominant limbs were not importantly altered by the familiarization. In opposite, non-dominant limbs showed large variations. New evidence is provided about the positive effects of a single familiarization session to improve the reliability the isometric knee extension test for rapid force production assessment. Coaches and practitioners may benefit of from these findings to conduct practical and reliable assessments of the rapid force production using a portable force sensor and a field-based approach.
\end{abstract}

Keywords: biomechanics; strain gauge; strength; power; muscle activation; resistance training

\section{Introduction}

Isometric strength of knee extensors has been widely assessed since decades due to its close relationship with functional performance [1-3] and as effective tool for monitoring injury rehabilitation success $[4,5]$. In recent years, the use of the isometric knee extension exercise during explosive or ballistic contractions has attracted increasing attention as an effective method to test and improve force production during rapid muscle activation, with positive transfers to sport-specific performance such as jumping or sprinting [6-8]. Despite its practical implications, however, the stable measurement of rapid force production remains of ongoing concern $[9,10]$. Hence, further understanding of best-practice and testing procedures that can aid the development of effective assessment continues to be of importance. 
Current resistance training practices involve the use of technology to obtain real-time data about neural and muscular determinants of performance [11,12]. Muscular determinants during isometric exercises are conventionally assessed by the maximal voluntary concentric force (MVC), which refers to the highest force the individual is able to produce during the test $[7,13]$. The MVC is demonstrated as a reliable and easy-to-obtain variable during the isometric knee extension test with portable force sensors $[14,15]$. However, while most of sport-related movements (i.e., jumping, sprinting, kicking) involves rapid contraction times (50-250 ms), the MVC is typically reached at later phases $\geq 300 \mathrm{~ms}$, which may limits its ability to explain performance for rapid actions $[13,16]$.

In turn, the ability to produce force rapidly $(<250 \mathrm{~ms})$ mostly relies on neural determinants such as motor unit recruitment, discharge rates and force twitches [8,12]. Neural factors are commonly assessed during isometric tests by the rate of force development (RFD) exerted within the early phase of rising muscle force, and the contractile impulse that can be produced within a given contraction time [16,17]. Despite the rising interest in the use of isometric testing to determine improvements in ballistic sport-specific movements [6,7], the design of practical field-based methods to obtain reliable RFD and impulse measures at different phases of the contraction is an ongoing challenge [18-21]. This is further confounded by the fact that the measurement of both RFD and impulse is highly dependent to the testing procedures $[9,10]$, the signal filtering [19] and the warm-up [22]. Hence, a further examination of the quality and consistency of the RFD and impulse measures is of critical importance.

To provide these insights would have practical implications for coaches and therapists, since nowadays one can easily collect automatically RFD and impulse data while providing real-time visual feedback using low cost, portable force sensors attached to a bench or table [9]. To the best of our knowledge, only one previous study has examined the reliability of rapid force production variables during the knee extension [21]. Albeit showing promising results, the fact that they conduced time-consuming testing procedures (separate tests for MVC and RFD which doubled the time required) makes difficult to transfer their results into the sport daily practice thus requires a field-based replication. Furthermore, despite side-to-side asymmetry in quadriceps RFD has gained interest as a screening tool for injury management [23], little is known about the differences between dominant and non-dominant limbs when testing the rapid force production during the knee extension test in athletes. Besides, there is no quantitative data describing the influence of a familiarization session to maximise the reliability of RFD during the knee extension strength test [9].

Therefore, the current study aimed to determine the intra-session and test-retest reliability of a rapid, isometric knee extension test to evaluate the MVC, RFD and impulse on both limbs in young athletes unfamiliar with the test, following a field-based approach. Based on the existing literature, we hypothesize that late contractions $>250$ ms would reach sufficient reliability since the first session, whilst earlier phases would require a previous familiarization.

\section{Materials and Methods}

\subsection{Experimental Design}

Participants completed the isometric knee extension test in two testing sessions (with $48 \mathrm{~h}$ rest) according to the evidence-based standards for RFD measurement [9]. Before each session, participants completed the same specific warm-up including rapid response neuromuscular activation to maximize the isometric knee extension performance [22]. Evaluations were performed under similar climatological conditions $\left(21-24^{\circ} \mathrm{C}\right.$ and $45-55 \%$ relative humidity) at the same time of day (16:00-19:00 h). All participants were previously screened to ensure they were able to complete the tests safety. However, they were unfamiliar with the isometric knee extension test. After the initial screen and the warm-up, participants completed three trials per leg of the aforementioned test. Measures for the force-time curve were automatically obtained using a portable strain gauge. 


\subsection{Participants}

Fourteen male athletes (Mean \pm SD: age $22.4 \pm 3.9$ years, body mass $81.2 \pm 6.9 \mathrm{~kg}$, height: $179.9 \pm 5.2 \mathrm{~cm}$ ) volunteered to participate in this study. All participants were fit, uninjured and not taking medications that could alter performance. To ensure they initiated the study with a comparable training base, all participants completed a one-maximum repetition test (1RM) for the full-squat exercise the week before to the experiment $(1 \mathrm{RM}=121.2 \pm 14.5 \mathrm{~kg}$; relative strength ratio $=1.5 \pm 0.2 \mathrm{~kg} / \mathrm{body}$ mass). However, they were unfamiliar with the isometric knee extension test. Participants signed a written informed consent form. The study was conducted conform to the Code of Ethics of the World Medical Association (Declaration of Helsinki) and approved by the Bioethics Commission of the local university.

\subsection{Rapid Isometric Contraction of the Knee Extensors}

Participants performed a specific warm-up including 2 sets of $6 \mathrm{~s}$ of three rapid response neuromuscular activation exercises: base rotations, side to side over line and 2 inch runs [22]. After the warm-up, participants sat on a custom-built bench, $70 \mathrm{~cm}$ high (Figure 1). A portable strain gauge with incorporated software (Chronojump, Barcelona, Spain) sampling at $80 \mathrm{~Hz}$ was secured at one end to the bench at $45 \mathrm{~cm}$ from the floor, and attached at the other to a chain connected to a resistant padded anklet, specifically designed for maximal isometric testing, to guarantee the mechanical rigidity and minimize joint movement [9]. The chain length was adapted to each participant's anthropometric characteristics to achieve the mechanical rigidity with a comfortable knee joint angle of $110^{\circ}$. Before each trial, knee flexion was measured using a handled goniometer (Nexgen Ergonomics, Point Claire, Quebec, Canada). The strain gauge was calibrated prior to each session using a $5 \mathrm{~kg}$ Eleiko disc (Eleiko, Halmstad, Sweden), according to the manufacturer's specifications. Participants completed three rapid contractions with $30 \mathrm{~s}$ rest [24]. Baseline conditions were standardized and monitored using real-time visual feedback provided by the manufacturer's software, to avoid alterations in the measure due to initial pre-tension and countermovement $[9,10,25]$. Participants were instructed to contract as "fast and hard" as possible with the emphasis on the explosive/ballistic phase of contraction during $2 \mathrm{~s}$ with strong verbal encouragement $[9,26]$.

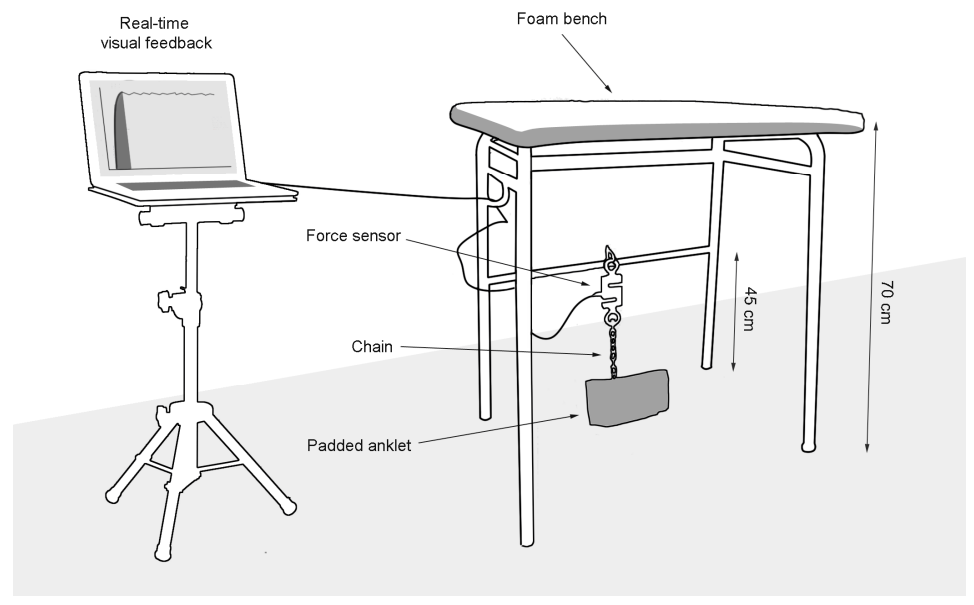

Figure 1. Isometric knee extension test set-up. The portable strain gauge secured at one end to the bench at $45 \mathrm{~cm}$ from the floor, and attached at the other to a chain connected to a resistant padded ankle. Visual feedback was given in real time using a computer software.

\subsection{Force Variables}

Measures for the force-time curve were automatically obtained using the manufacturer's software for windows (Chronojump 1.9.0, Barcelona, Spain). Results from each of the three trials were used for the intra-session analysis, whereas the trial with the highest values was used for the test-retest 
reliability analysis [9]. This software provides values in raw (original signal) and fitted (inverse monoexponentially function that better fits the raw data). This fitting is made by adjusting the Fmax (maximum force, i.e., MVC) and tau ( $\tau$, the time necessary to reach the $63.2 \%$ of the Fmax), as follows:

$$
\mathrm{F}=\operatorname{Fmax} \times\left(1-\mathrm{e}^{\wedge}(1 / \tau)\right)
$$

The following variables were calculated (Figure 2):

- Maximal voluntary contraction force (MVC): instantaneous maximal isometric muscle strength in Newtons (N).

- Rate of force development (RFD): the contractile RFD was obtained from the slope of the force-time curve $\left(\Delta\right.$ Force/ $\Delta$ time) expressed in $\mathrm{N} \cdot \mathrm{s}^{-1}$; thus, the instantaneous RFD peak $\left(\mathrm{RFD}_{\max }\right)$ was the highest slope of the curve [17]. Average RFD was calculated for three overlapping periods in milliseconds to collect measures in three different phases of the contraction: 0-50 ms ( $\left.\operatorname{RFD}_{0-50}\right)$, 0-150 ms ( $\left.\operatorname{RFD}_{0-150}\right)$ and 0-250 ms (RFD $\left.0-250\right)[9,27]$.

- Impulse: the impulse was calculated through integration of force over time (i.e., cumulated area under the force-time curve) expressed in N.s [17]. Average impulse was calculated for the same three overlapping RFD periods in milliseconds (Impulse $e_{-50}$, Impulse $e_{0-150}$ and Impulse I $_{0-250}$ )

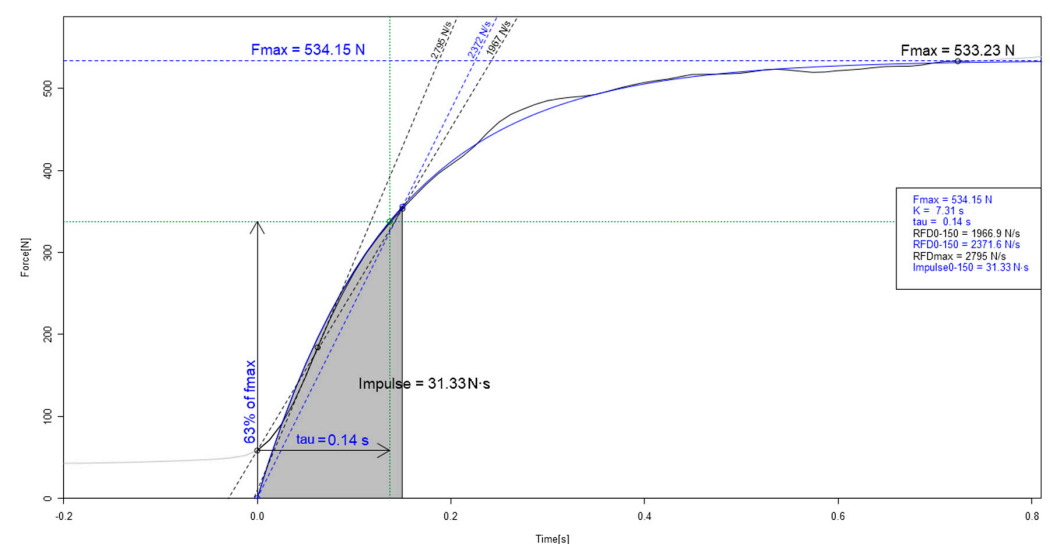

Figure 2. Example (screen-capture obtained from the force sensor software) of some parameters for the force-time curve during the maximal isometric knee extension test. Raw data (original signal) are in black. Fitted data (inverse monoexponentially function that better fits the raw data) are in grey. Note: Fmax is named as maximal voluntary concentric force (MVC) in the present manuscript.

\subsection{Statistical Analysis}

Reliability and level of agreement between the force variables within (intra-session) and between (test-retest) sessions were determined by the intraclass correlation coefficient (ICC), standard error of the measurement (SEM) and coefficient of variation (CV). Two-way mixed-effects, absolute agreement model in ICC was conducted according to guidelines for test-retest and intrarater reliability [28]. The SEM was calculated from the square root of the mean square error term in a repeated-measures ANOVA to determine the measurement error and between-participant variability [29]. The CV was calculated relative to the SEM as a percentage $(\mathrm{CV}=100 \mathrm{SEM} / \mathrm{mean})$ [29]. Criteria for acceptable reliability were set for very high $(\mathrm{CV} \leq 5 \%$, ICC $\geq 0.90)$, high $(\mathrm{CV} \leq 10 \%$, ICC $>0.90)$ and moderate $(\mathrm{CV} \leq 15 \%$, ICC $>0.80)$ according to previous studies testing the reliability of RFD and impulse during isometric exercises [19-21]. Inter-limb asymmetries $>15 \%$ were considered as high [30]. Normal distribution was verified by Kolmogorov-Smirnov tests. Student's $t$-test for paired samples was performed to identify significant differences $(p<0.05)$ between the test and retest conditions. Effect size (ES) was calculated [31] to estimate the magnitude of the differences using the Hedges' $g$ and interpreted as low (0.20) medium (0.50) and high (0.80). 


\section{Results}

\subsection{Intra-Session Reliability}

Tables 1 and 2 show the intra-session reliability in raw (original data) and fitted (filtered data),

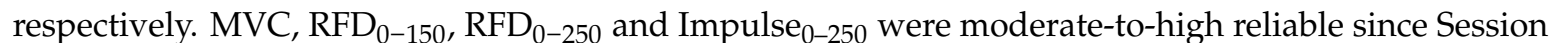
1 in both raw (CV ranges: 7.0 to $13.3 \%$, ICC ranges: 0.887 to 0.976 ) and fitted (CV ranges: 5.9 to $12.2 \%$, ICC ranges: 0.921 to 0.958 ) data. These results improved in Session 2 up to showing a high reliability in both raw and fitted $(\mathrm{CV} \leq 9.3 \% \mathrm{ICC} \geq 0.958)$. Additionally, Impulse ${ }_{0-150}$ reached an acceptable reliability in Session 2 (CV $\leq 11.9 \%$ ICC $\geq 0.954)$, with slightly better results in fitted data. $\mathrm{RFD}_{0-50}$ was readable with a moderate reliability $(\mathrm{CV} \leq 13.6 \% \mathrm{ICC} \geq 0.941)$ in Session 2 with fitted signal. Impulse ${ }_{0-50}$ showed nearly reliable readings in Session 2 with fitted signal $(\mathrm{CV} \leq 15.8 \%$ ICC $\geq 0.929$ ). RFD $_{\max }$ achieved moderately reliable records in Session 2 but only in dominant leg raw data. Fitted data were equally reliable for dominant and non-dominant legs, whilst raw data showed particular differences. Asymmetries trended to diminish after the familiarization, especially during early phases of contraction (0-50 ms), with all the participants showing optimal values $<15 \%$ in the second session.

Table 1. Intra-session reliability in maximal voluntary contraction force (MVC), impulse, and rate of force development (RFD) variables for original data (raw).

\begin{tabular}{|c|c|c|c|c|c|c|c|c|c|}
\hline \multirow{2}{*}{ Raw Data } & \multicolumn{4}{|c|}{ Dominant Leg } & \multicolumn{4}{|c|}{ Non-Dominant Leg } & \multirow{2}{*}{ Diff $\%$} \\
\hline & M (SD) & $\mathrm{CV}$ & SEM & ICC & M (SD) & $\mathrm{CV}$ & SEM & ICC & \\
\hline \multicolumn{10}{|l|}{$\operatorname{MVC}(N)$} \\
\hline Session 1 & 649 (115) & $9.1 \%$ & 59.9 & 0.887 & $598(91)$ & $5.8 \%$ & 34.0 & 0.869 & $-8.9 \%$ \\
\hline Session 2 & $676(117)$ & $5.0 \%$ & 33.9 & 0.966 & $618(102)$ & $4.4 \%$ & 26.9 & 0.975 & $-8.3 \%$ \\
\hline \multicolumn{10}{|c|}{ Impulse $_{0-50}(N \cdot s)$} \\
\hline Session 1 & $7.1(3.7)$ & $37.8 \%$ & 2.6 & 0.788 & $6.2(3.3)$ & $29.3 \%$ & 1.8 & 0.896 & $-10.2 \%$ \\
\hline Session 2 & $7.6(3.1)$ & $30.3 \%$ & 2.2 & 0.798 & $7.3(3.3)$ & $21.5 \%$ & 1.6 & 0.815 & $-2.4 \%$ \\
\hline \multicolumn{10}{|c|}{ Impulse $_{0-150}(N \cdot s)$} \\
\hline Session 1 & $48.6(15.1)$ & $16.0 \%$ & 7.8 & 0.910 & $42.9(14.0)$ & $11.9 \%$ & 5.1 & 0.956 & $-13.1 \%$ \\
\hline Session 2 & $49.5(14.0)$ & $10.7 \%$ & 5.3 & 0.954 & $45.8(13.5)$ & $16.6 \%$ & 7.6 & 0.909 & $-8.0 \%$ \\
\hline \multicolumn{10}{|c|}{ Impulse $_{0-250}(N \cdot s)$} \\
\hline Session 1 & $102.8(26.2)$ & $11.7 \%$ & 12.0 & 0.928 & $93.4(24.8)$ & $8.2 \%$ & 7.7 & 0.969 & $-10.0 \%$ \\
\hline Session 2 & $105.1(25.1)$ & $6.7 \%$ & 7.0 & 0.976 & $96.6(24.1)$ & $12.7 \%$ & 12.2 & 0.926 & $-8.8 \%$ \\
\hline \multicolumn{10}{|l|}{$\operatorname{RFD}_{0-50}\left(N \cdot s^{-1}\right)$} \\
\hline Session 1 & $4446(2275)$ & $34.8 \%$ & 1548 & 0.802 & 3959 (2209) & $26.9 \%$ & 1064 & 0.914 & $-12.4 \%$ \\
\hline Session 2 & 4667 (1951) & $21.8 \%$ & 1016 & 0.901 & 4256 (1989) & $32.1 \%$ & 1367 & 0.816 & $-9.7 \%$ \\
\hline \multicolumn{10}{|c|}{$\operatorname{RFD}_{0-150}\left(N \cdot s^{-1}\right)$} \\
\hline Session 1 & 3074 (695) & $8.3 \%$ & 254 & 0.956 & $2771(706)$ & $13.3 \%$ & 369 & 0.934 & $-10.9 \%$ \\
\hline Session 2 & $3087(760)$ & $8.0 \%$ & 247 & 0.966 & $2881(677)$ & $9.3 \%$ & 268 & 0.959 & $-7.2 \%$ \\
\hline \multicolumn{10}{|c|}{$\operatorname{RFD}_{0-250}\left(N \cdot s^{-1}\right)$} \\
\hline Session 1 & $2122(426)$ & $7.0 \%$ & 148 & 0.959 & $1954(430)$ & $9.6 \%$ & 189 & 0.950 & $-8.6 \%$ \\
\hline Session 2 & $2211(491)$ & $7.7 \%$ & 170 & 0.958 & $2010(393)$ & $6.0 \%$ & 122 & 0.968 & $-10.0 \%$ \\
\hline \multicolumn{10}{|l|}{$\operatorname{RFD}_{\max }\left(N \cdot s^{-1}\right)$} \\
\hline Session 1 & $6988(2278)$ & $16.2 \%$ & 1135 & 0.912 & 6118 (1933) & $21.3 \%$ & 1302 & 0.944 & $-14.2 \%$ \\
\hline Session 2 & 7098 (2346) & $12.7 \%$ & 899 & 0.952 & $6800(1858)$ & $24.4 \%$ & 1660 & 0.874 & $-4.4 \%$ \\
\hline
\end{tabular}

SEM: standard error of measurement, CV: SEM expressed as a coefficient of variation, ICC: intraclass correlation coefficient. Diff \%: percentage of difference between dominant and non-dominant leg.

Table 2. Intra-session reliability in maximal voluntary contraction force (MVC), rate of force development (RFD) and impulse variables for filtered data (fitted).

\begin{tabular}{|c|c|c|c|c|c|c|c|c|c|}
\hline \multirow{2}{*}{ Fitted Data } & \multicolumn{4}{|c|}{ Dominant Leg } & \multicolumn{4}{|c|}{ Non-Dominant Leg } & \multirow{2}{*}{$\%$ Diff } \\
\hline & M (SD) & $\mathrm{CV}$ & SEM & ICC & M (SD) & $\mathrm{CV}$ & SEM & ICC & \\
\hline \multicolumn{10}{|l|}{$\operatorname{MVC}(N)$} \\
\hline Session 1 & $628(111)$ & $5.9 \%$ & 37.7 & 0.887 & $568(93)$ & $6.2 \%$ & 35.2 & 0.869 & $-10.5 \%$ \\
\hline Session 2 & $646(117)$ & $5.6 \%$ & 35.9 & 0.969 & $597(96)$ & $4.7 \%$ & 27.9 & 0.975 & $-8.2 \%$ \\
\hline \multicolumn{10}{|l|}{ Impulse $_{0-50}(N \cdot s)$} \\
\hline Session 1 & $7.6(2.9)$ & $22.6 \%$ & 1.7 & 0.788 & $7.3(2.6)$ & $25.8 \%$ & 1.9 & 0.815 & $-15.9 \%$ \\
\hline Session 2 & $7.7(2.8)$ & $15.8 \%$ & 1.2 & 0.798 & $6.5(2.6)$ & $15.1 \%$ & 1.0 & 0.896 & $-5.3 \%$ \\
\hline \multicolumn{10}{|c|}{ Impulse $_{0-150}(N \cdot s)$} \\
\hline Session 1 & $48.4(14.6)$ & $15.7 \%$ & 7.6 & 0.910 & $43.1(13.5)$ & $10.6 \%$ & 4.6 & 0.956 & $-12.3 \%$ \\
\hline Session 2 & $49.3(13.8)$ & $9.8 \%$ & 4.8 & 0.954 & $46.1(12.7)$ & $15.0 \%$ & 6.9 & 0.909 & $-6.8 \%$ \\
\hline \multicolumn{10}{|c|}{ Impulse $_{0-250}(N \cdot s)$} \\
\hline Session 1 & $102.8(26.4)$ & $11.7 \%$ & 12.1 & 0.928 & $96.4(23.8)$ & $12.6 \%$ & 12.1 & 0.926 & $-8.8 \%$ \\
\hline Session 2 & $104.9(25.3)$ & $7.1 \%$ & 7.4 & 0.976 & $93.3(25.0)$ & $8.4 \%$ & 7.8 & 0.969 & $-10.2 \%$ \\
\hline
\end{tabular}


Table 2. Cont.

\begin{tabular}{|c|c|c|c|c|c|c|c|c|c|}
\hline \multirow{2}{*}{ Fitted Data } & \multicolumn{4}{|c|}{ Dominant Leg } & \multicolumn{4}{|c|}{ Non-Dominant Leg } & \multirow{2}{*}{$\%$ Diff } \\
\hline & M (SD) & $\mathrm{CV}$ & SEM & ICC & M (SD) & $\mathrm{CV}$ & SEM & ICC & \\
\hline \multicolumn{10}{|l|}{$\operatorname{RFD}_{0-50}\left(N \cdot s^{-1}\right)$} \\
\hline Session 1 & 5465 (2000) & $21.2 \%$ & 1161 & 0.802 & 4801 (1756) & $13.6 \%$ & 651 & 0.914 & $-13.8 \%$ \\
\hline Session 2 & 5589 (1840) & $13.6 \%$ & 761 & 0.901 & 5308 (1637) & $18.7 \%$ & 991 & 0.816 & $-5.3 \%$ \\
\hline \multicolumn{10}{|l|}{$\operatorname{RFD}_{0-150}\left(N \cdot s^{-1}\right)$} \\
\hline Session 1 & 3315 (850) & $12.2 \%$ & 406 & 0.956 & 3119 (766) & $11.5 \%$ & 358.2 & 0.934 & $-6.3 \%$ \\
\hline Session 2 & 3411 (808) & $6.8 \%$ & 232 & 0.966 & $3042(790)$ & $8.1 \%$ & 244.9 & 0.959 & $-12.1 \%$ \\
\hline \multicolumn{10}{|l|}{$\operatorname{RFD}_{0-250}\left(N \cdot s^{-1}\right)$} \\
\hline Session 1 & $2318(463)$ & $8.1 \%$ & 188 & 0.959 & $2120(457)$ & $8.5 \%$ & 181 & 0.950 & $-9.3 \%$ \\
\hline Session 2 & 2365 (484) & $5.3 \%$ & 126 & 0.958 & 2142 (448) & $5.9 \%$ & 126 & 0.968 & $-10.4 \%$ \\
\hline \multicolumn{10}{|l|}{$\operatorname{RFD}_{\text {max }}\left(N \cdot s^{-1}\right)$} \\
\hline Session 1 & 7561 (3447) & $28.8 \%$ & 2179 & 0.912 & $6363(2892)$ & $18.9 \%$ & 1202 & 0.874 & $-21.3 \%$ \\
\hline Session 2 & 7721 (3340) & $21.3 \%$ & 1644 & 0.952 & 7459 (2763) & $24.9 \%$ & 1856 & 0.944 & $-1.4 \%$ \\
\hline
\end{tabular}

SEM: standard error of measurement, CV: SEM expressed as a coefficient of variation, ICC: intraclass correlation coefficient. Diff \%: percentage of difference between dominant and non-dominant leg.

\subsection{Test-Retest Reliability}

Results from the test-retest reliability are shown in Table 3. MVC, RFD $_{0-250}$ and Impulse ${ }_{0-250}$ maintained a high reliability among sessions for both raw and fitted data (CV $\leq 9.2 \%$ ICC $\geq 0.904)$. However, $\mathrm{RFD}_{0-150}$ and Impulse ${ }_{0-150}$ were highly reliable in fitted data $(\mathrm{CV} \leq 10.8 \%$ ICC $\geq 0.879)$. Likewise, $\mathrm{RFD}_{0-50}$ and Impulse ${ }_{0-50}$ were only deemed reliable in fitted data and particularly in the dominant leg (CV $\leq 13.3 \%$ ICC $\geq 0.898)$. $R_{F D} D_{\max }$ was best in the dominant leg, with similar results in fitted and raw data ( $C V \sim 17 \%$ ICC $\geq 0.799)$. Dominant limb records were not importantly altered by the familiarization $\left(\mathrm{ES}<0.13\right.$ ) except for the $\mathrm{RFD}_{0-250}$. In opposite, non-dominant limbs showed large variations in the majority of the variables but the $\mathrm{RFD}_{0-250}$.

\section{Discussion}

The main findings of this study indicate that: (i) RFD and impulse during the isometric knee extension tests can be assessed with high reliability during "late" phases of the contraction (0-250 ms) since the first session, following a field-based approach, in young athletes unfamiliar with the test; (ii) earlier phases of the contraction $(0-150 \mathrm{~ms})$ can be measured with moderate reliability after one familiarization session; (iii) in contrast, measures at 0-50 ms requires larger sampling rates and/or longer familiarization to reach sufficient reliability; (iv) the results confirm previous findings that knee extension MVC can be accurately assessed using portable force sensors [14,15].

The development of practical methods to obtain reliable RFD and impulse parameters from sport-related actions is an ongoing challenge in sport practice $[9,10]$, since they may inform about the neural efficiency of motor skill performance [8]. According to our findings, RFD and impulse at 0-150 ms and 0-250 ms can be measured with sufficient reliability $(\mathrm{CV}<10 \%)$ after one familiarization session during the isometric knee extension tests, with better results if filtering the data. These good results were automatically obtained using a portable low-cost force sensor at $80 \mathrm{~Hz}$ which make possible to easily reproduce this assessment in both athletic and clinic (e.g., hospitals, rehabilitation centres or nursing homes) environments. In contrast, the lower reliability even with fitted data $(\mathrm{CV} \sim 14 \%)$ found in earlier phases of contractions $(0-50 \mathrm{~ms})$ suggests the need of higher sampling rate equipment and/or experienced participants. This is in line with Buckthorpe et al. [21] who found good within-participants reliability from $100 \mathrm{~ms}$ onward but high variation up to $\mathrm{CV}=19 \%$ at earlier phases ( $\mathrm{RFD}_{0-50}$ and Impulse $\left.{ }_{0-50}\right)$ during a rapid, isometric knee extension test after familiarization. Since we used a much lower sampling rate $(80 \mathrm{~Hz}$ vs. $2000 \mathrm{~Hz})$, the current improvements could be attributable to methodological differences such as the inclusion of a rapid-response warm-up [22]. Further, in light of our findings, to collect MVC and RFD together from the same trial via evidence-based guidelines [9] seems advantageable as may increase performance and reduce fatigue as a result of performing less trials while saving time. Of interest, adopting an external focus of attention (e.g., "try to touch this target") seems to be beneficial when testing rapid contractions of the knee extensors [32]. Future studies 
should examine whether the use of external attentional focus may have an acute impact on the reliability of rapid force production measures during the isometric knee extension tests, specially at early phases of the contraction $(0-50 \mathrm{~ms})$.

Table 3. Test-retest reliability (values of the highest trial conducted in Sessions 1 and 2) in maximal voluntary contraction force (MVC), rate of force development (RFD) and impulse variables for original (raw) and filtered (fitted) data.

\begin{tabular}{|c|c|c|c|c|c|c|c|c|c|c|c|c|}
\hline \multirow{2}{*}{ Test-Retest } & \multicolumn{6}{|c|}{ Dominant Leg } & \multicolumn{6}{|c|}{ Non-Dominant Leg } \\
\hline & $\mathrm{CV}$ & SEM & ICC & $\%$ Diff & $p$ & ES & $\mathrm{CV}$ & SEM & ICC & $\%$ Diff & $p$ & ES \\
\hline \multicolumn{13}{|l|}{ Raw } \\
\hline $\operatorname{MVC}(N)$ & $5.7 \%$ & 38.0 & 0.948 & $+2.5 \%$ & 0.290 & 0.14 & $5.4 \%$ & 33.4 & 0.939 & $+2.7 \%$ & 0.248 & 0.17 \\
\hline $\operatorname{Impulse}_{0-50}(N \cdot s)$ & $19.7 \%$ & 1.8 & 0.801 & $+1.1 \%$ & 0.882 & 0.03 & $24.1 \%$ & 1.9 & 0.713 & $-19.6 \%$ & 0.075 & 0.50 \\
\hline Impulse $_{0-150}(N \cdot s)$ & $10.0 \%$ & 5.4 & 0.908 & $-0.6 \%$ & 0.891 & 0.02 & $11.4 \%$ & 5.6 & 0.955 & $-6.5 \%$ & 0.154 & 0.26 \\
\hline Impulse $_{0-250}(N \cdot s)$ & $9.2 \%$ & 10.2 & 0.904 & $<0.1 \%$ & 0.994 & 0.01 & $7.4 \%$ & 7.5 & 0.929 & $-3.5 \%$ & 0.265 & 0.17 \\
\hline $\operatorname{RFD}_{0-50}\left(N \cdot \mathrm{s}^{-1}\right)$ & $15.6 \%$ & 868 & 0.848 & $-1.1 \%$ & 0.870 & 0.04 & $23.7 \%$ & 1184 & 0.742 & $-7.6 \%$ & 0.497 & 0.19 \\
\hline $\operatorname{RFD}_{0-150}\left(\mathrm{~N} \cdot \mathrm{s}^{-1}\right)$ & $8.7 \%$ & 283 & 0.914 & $-0.1 \%$ & 0.980 & 0.01 & $10.4 \%$ & 313 & 0.840 & $+2.9 \%$ & 0.530 & 0.14 \\
\hline $\operatorname{RFD}_{0-250}\left(\mathrm{~N} \cdot \mathrm{s}^{-1}\right)$ & $7.3 \%$ & 165 & 0.938 & $+5.0 \%$ & 0.081 & 0.24 & $5.7 \%$ & 120 & 0.952 & $-0.1 \%$ & 0.982 & 0.01 \\
\hline $\begin{array}{l}\operatorname{RFD}_{\max }\left(N \cdot s^{-1}\right) \\
\text { Fitted }\end{array}$ & $17.2 \%$ & 1349 & 0.799 & $-0.8 \%$ & 0.918 & 0.03 & $22.0 \%$ & 1658 & 0.212 & $+14.5 \%$ & 0.095 & 0.67 \\
\hline $\operatorname{MVC}(N)$ & $6.1 \%$ & 40.0 & 0.938 & $+2.4 \%$ & 0.306 & 0.13 & $5.0 \%$ & 30.2 & 0.947 & $+2.5 \%$ & 0.261 & 0.15 \\
\hline Impulse $_{0-50}(N \cdot s)$ & $13.3 \%$ & 1.2 & 0.901 & $-0.5 \%$ & 0.932 & 0.02 & $17.1 \%$ & 1.4 & 0.810 & $-16.4 \%$ & 0.030 & 0.49 \\
\hline Impulse $_{0-150}(N \cdot s)$ & $10.5 \%$ & 5.6 & 0.900 & $-0.4 \%$ & 0.937 & 0.01 & $10.8 \%$ & 5.3 & 0.879 & $-7.0 \%$ & 0.146 & 0.28 \\
\hline Impulse $_{0-250}(\mathrm{~N} \cdot \mathrm{s})$ & $9.1 \%$ & 10.1 & 0.904 & $+0.3 \%$ & 0.942 & 0.01 & $7.5 \%$ & 7.7 & 0.925 & $-3.5 \%$ & 0.311 & 0.16 \\
\hline $\operatorname{RFD}_{0-50}\left(N \cdot s^{-1}\right)$ & $12.4 \%$ & 778 & 0.898 & $-0.6 \%$ & 0.906 & 0.02 & $14.8 \%$ & 841 & 0.823 & $-10.5 \%$ & 0.115 & 0.38 \\
\hline $\operatorname{RFD}_{0-150}\left(N \cdot s^{-1}\right)$ & $8.9 \%$ & 318 & 0.907 & $+0.4 \%$ & 0.923 & 0.02 & $6.5 \%$ & 218 & 0.940 & $-2.6 \%$ & 0.411 & 0.21 \\
\hline $\operatorname{RFD}_{0-250}\left(\mathrm{~N} \cdot \mathrm{s}^{-1}\right)$ & $7.1 \%$ & 173 & 0.930 & $+0.3 \%$ & 0.925 & 0.01 & $4.6 \%$ & 102 & 0.967 & $-0.1 \%$ & 0.958 & 0.01 \\
\hline $\operatorname{RFD}_{\max }\left(N \cdot s^{-1}\right)$ & $16.9 \%$ & 1548 & 0.891 & $-0.2 \%$ & 0.975 & 0.01 & $22.9 \%$ & 1864 & 0.717 & $-17.3 \%$ & 0.106 & 0.45 \\
\hline
\end{tabular}

SEM: standard error of measurement, CV: SEM expressed as a coefficient of variation, ICC: intraclass correlation coefficient, Diff: percentage of change between the average records of each session, $p$-value: $t$-test significance, ES: Hedge's $g$ effect size.

A main practical resource herein provided for a better understanding of the isometric knee extension test reliability is the reporting of intra-session and test-retest differences in absolute terms (i.e., SEM). This information assists in the interpretation of results from a practical viewpoint. A large SEM relative to the between-participant variance contributes to poor reliability. In other words, if we would like to compare the differences after a training program, changes greater that the SEM would be likely to be a result of the intervention rather than a measurement error [29]. Accordingly, taking the Session 2 fitted readings and the dominant leg reference (Table 2), the current field-based method would permit us to identify, at least, changes in MVC over $35.9 \mathrm{~N}$ or changes in $\mathrm{RFD}_{0-250}$ and Impulse ${ }_{0-250}$ from $126 \mathrm{~N} \cdot \mathrm{s}^{-1}$ and $7.4 \mathrm{~N} \cdot \mathrm{s}$ respectively. Hence, despite we cannot deny the existence of a high intra-individual variability during an isometric leg extension test [21], the use of evidence-based protocols, rapid-response warm-up and visual feedback make it possible to obtain a reliable RFD/Impulse measurement with field-based, portable and low-cost equipment. This is particularly relevant for coaches and sport clubs dealing with athletes with similar strength status than our sample (MVC from $\sim 500$ to $\sim 850 \mathrm{~N}$; 7- to 10-fold their body mass).

The implications of these findings are that using a portable force sensor under proper measurement guidelines allows to collect reliable RFD, Impulse and MVC data (altogether from the same trial) to evaluate the rapid isometric contraction of the knee extensors in young athletes. Such knowledge, along with the interpretation of the measurement errors, will aid both in the assessment of performance at a given time-point (e.g., pre-season, tapering, diagnostic analysis) and the identification of true changes due to training-induce adaptations (e.g., training program, injury rehabilitation). In addition, we provide new quantitative data describing the influence of familiarization during RFD assessment [9], with some variables reaching sufficient reliability since the first session and the others requiring just a single previous session (Table 2). Of final note is that important inter-limb asymmetries were identified, with non-dominant limbs describing lower records and larger variations during rapid force assessment. Although these differences could be anticipated [30], it seems to be the first time presenting data about asymmetries and RFD performance during a ballistic knee extension test in athletes. According to our findings, this test would allow to identify severe asymmetries $>15 \%$ but requiring a previous familiarization. All in all, given that improvements in RFD can be expected within the first 
weeks of training [6], and the benefits of a previous familiarization, it is advisable to evaluate the rapid isometric contraction of the knee extensors since initial stages of the season and conducted frequent monitoring to verify short-term progresses.

\section{Conclusions}

New evidence and practical guidelines are provided to collect reliable RFD and Impulse measures of the knee extensors regarding the contraction time, the preferable signal and the influence of familiarization (Table 4). The use of a portable force sensor and a field-based approach may benefit coaches and practitioners from these findings by conducting practical and reliable methods for rapid force production assessment outside the laboratory. Under proper methods, coaches and clinicians dealing with rapid force production training and/or assessment might rely on both MVC and RFD/Impulse at $0-250 \mathrm{~ms}$ since the very first session if a familiarization is not possible. However, it seems necessary to complete at least one familiarization session to collect RFD and Impulse 0-150 with moderate reliability. In turn, very rapid contractions (0-50 ms and $R_{F D} D_{\max }$ ) would require longer preparation. Frequent unilateral monitoring over time is advisable to determine side-to-side asymmetry in quadriceps RFD.

Table 4. Recommendations on maximal isometric knee extension force assessment based on reliability (intra-session level of agreement), preferable signal (raw: original; fitted: filtered) and the influence of a familiarization session (test-retest differences).

\begin{tabular}{|c|c|c|c|c|}
\hline Isometric Knee Extension Force & Reliability & Preferable Signal & Influence of Familiarization & Inter-Limb Asymmetry \\
\hline $\operatorname{MVC}(N)$ & High & Raw/Fitted & Low & Low \\
\hline $\operatorname{RFD}_{0-250}\left(N \cdot s^{-1}\right)$ & High & Fitted & Low & low \\
\hline Impulse $_{0-250}(N \cdot s)$ & High & Raw/Fitted & Low & Moderate \\
\hline $\mathbf{R F D}_{0-150}\left(N \cdot \mathrm{s}^{-1}\right)$ & Moderate & Raw/Fitted & High & Moderate \\
\hline Impulse $_{0-150}(N \cdot s)$ & Moderate & Fitted & High & High \\
\hline $\operatorname{RFD}_{0-50}\left(N \cdot s^{-1}\right)$ & Moderate & Fitted & Very high & High \\
\hline Impulse $_{0-50}(N \cdot s)$ & Low & Fitted & Very high & Very high \\
\hline $\operatorname{RFD}_{\max }\left(N \cdot s^{-1}\right)$ & Low & Raw & Very high & Very high \\
\hline
\end{tabular}

Author Contributions: Conceptualization, J.C.-I. and J.G.P.; methodology, J.C.-I., A.H.-B., A.C.-M., J.G.P.; investigation, J.C.-I., A.H.-B., A.C.-M., formal analysis, J.C.-I., A.H.-B.; writing-original draft preparation, J.C.-I., A.H.-B.; writing-review and editing, J.C.-I., A.H.-B., A.C.-M., J.G.P. All authors have read and agreed to the published version of the manuscript.

Funding: This research received no external funding.

Acknowledgments: The authors thank Paco and Pedro for their valuable technical contribution in the development of the custom-built bench, and thank the participants for their involvement in this study.

Conflicts of Interest: The authors declare no conflict of interest.

\section{References}

1. De Ruiter, C.J.; Van Leeuwen, D.; Heijblom, A.; Bobbert, M.F.; De Haan, A. Fast unilateral isometric knee extension torque development and bilateral jump height. Med. Sci. Sports Exerc. 2006, 38, 1843-1852. [CrossRef]

2. Requena, B.; González-Badillo, J.J.; Saez De Villareal, E.S.; Ereline, J.; García, I.; Gapeyeva, H.; Pääsuke, M. Functional performance, maximal strength, and power characteristics in isometric and dynamic actions of lower extremities in soccer players. J. Strength Cond. Res. 2009, 23, 1391-1401. [CrossRef]

3. Bojsen-Møller, J.; Magnusson, S.P.; Rasmussen, L.R.; Kjaer, M.; Aagaard, P. Muscle performance during maximal isometric and dynamic contractions is influenced by the stiffness of the tendinous structures. J. Appl. Physiol. 2005, 99, 986-994. [CrossRef]

4. Maffiuletti, N.A.; Bizzini, M.; Widler, K.; Munzinger, U. Asymmetry in quadriceps rate of force development as a functional outcome measure in TKA. Clin. Orthop. Relat. Res. 2010, 468, 191-198. [CrossRef]

5. Gapeyeva, H.; Buht, N.; Peterson, K.; Ereline, J.; Haviko, T.; Pääsuke, M. Quadriceps femoris muscle voluntary isometric force production and relaxation characteristics before and 6 months after unilateral total knee arthroplasty in women. Knee Surg. Sports Traumatol. Arthrosc. 2007, 15, 202-211. [CrossRef] 
6. Blazevich, A.J.; Wilson, C.J.; Alcaraz, P.E.; Rubio, J.A. Effects of Resistance Training Movement Pattern and Velocity on Isometric Muscular Rate of Force Development: A Systematic Review with Meta-analysis and Meta-regression. Sports Med. 2020, 50, 943-963. [CrossRef]

7. Oranchuk, D.J.; Storey, A.G.; Nelson, A.R.; Cronin, J.B. Isometric training and long-term adaptations: Effects of muscle length, intensity, and intent: A systematic review. Scand. J. Med. Sci. Sports 2019, 29, 484-503. [CrossRef]

8. Folland, J.P.; Buckthorpe, M.W.; Hannah, R. Human capacity for explosive force production: Neural and contractile determinants. Scand. J. Med. Sci. Sports 2014, 24, 894-906. [CrossRef]

9. Maffiuletti, N.A.; Aagaard, P.; Blazevich, A.J.; Folland, J.; Tillin, N.; Duchateau, J. Rate of force development: Physiological and methodological considerations. Eur. J. Appl. Physiol. 2016, 116, 1091-1116. [CrossRef]

10. Rodríguez-Rosell, D.; Pareja-Blanco, F.; Aagaard, P.; González-Badillo, J.J. Physiological and methodological aspects of rate of force development assessment in human skeletal muscle. Clin. Physiol. Funct. Imaging 2018, 38, 743-762. [CrossRef]

11. McGuigan, M. Testing and Evaluation of Strength and Power; Routledge: Abingdon, UK, 2019; ISBN 0429647956.

12. Dideriksen, J.L.; Del Vecchio, A.; Farina, D. Neural and muscular determinants of maximal rate of force development. J. Neurophysiol. 2020, 123, 149-157. [CrossRef]

13. Andersen, L.L.; Aagaard, P. Influence of maximal muscle strength and intrinsic muscle contractile properties on contractile rate of force development. Eur. J. Appl. Physiol. 2006, 96, 46-52. [CrossRef]

14. Toonstra, J.; Mattacola, C.G. Test-retest reliability and validity of isometric knee-flexion and -extension measurement using 3 methods of assessing muscle strength. J. Sport Rehabil. 2013, 22, 1-5. [CrossRef]

15. Ruschel, C.; Haupenthal, A.; Jacomel, G.F.; de Fontana, H.B.; dos Santos, D.P.; Scoz, R.D.; Roesler, H. Validity and reliability of an instrumented leg-extension machine for measuring isometric muscle strength of the knee extensors. J. Sport Rehabil. 2015, 24, 1-4. [CrossRef] [PubMed]

16. Aagaard, P.; Simonsen, E.B.; Andersen, J.L.; Magnusson, P.; Dyhre-Poulsen, P. Increased rate of force development and neural drive of human skeletal muscle following resistance training. J. Appl. Physiol. 2002, 93, 1318-1326. [CrossRef] [PubMed]

17. Aagaard, P.; Simonsen, E.B.; Andersen, J.L.; Magnusson, P.; Dyhre-Poulsen, P. Neural adaptation to resistance training: Changes in evoked V-wave and H-reflex responses. J. Appl. Physiol. 2002, 92, 2309-2318. [CrossRef] [PubMed]

18. Dello Iacono, A.; Valentin, S.; Sanderson, M.; Halperin, I. The Isometric Horizontal Push Test: Test-Retest Reliability and Validation Study. Int. J. Sports Physiol. Perform. 2019, 15, 581-584. [CrossRef]

19. Moir, G.L.; Getz, A.; Davis, S.E.; Marques, M.; Witmer, C.A. The Inter-Session Reliability of Isometric Force-Time Variables and the Effects of Filtering and Starting Force. J. Hum. Kinet. 2019, 66, 43-55. [CrossRef]

20. Brady, C.J.; Harrison, A.J.; Flanagan, E.P.; Gregory Haff, G.; Comyns, T.M. A comparison of the isometric midthigh pull and isometric squat: Intraday reliability, usefulness, and the magnitude of difference between tests. Int. J. Sports Physiol. Perform. 2018, 13, 844-852. [CrossRef]

21. Buckthorpe, M.W.; Hannah, R.; Pain, T.G.; Folland, J.P. Reliability of neuromuscular measurements during explosive isometric contractions, with special reference to electromyography normalization techniques. Muscle Nerve 2012, 46, 566-576. [CrossRef]

22. Oranchuk, D.J.; Switaj, Z.J.; Zuleger, B.M. The Addition of a "Rapid Response" Neuromuscular Activation To a Standard Dynamic Warm-Up Improves Isometric Force and Rate of Force Development. J. Aust. Strength Cond. 2017, 25, 19-24.

23. Buckthorpe, M.W.; Roi, G.S. The time has come to incorporate a greater focus on rate of force development training in the sports injury rehabilitation process. Muscles Ligaments Tendonsj. 2017, 7, 435. [CrossRef]

24. Tillin, N.A.; Jimenez-Reyes, P.; Pain, M.T.G.; Folland, J.P. Neuromuscular performance of explosive power athletes versus untrained individuals. Med. Sci. Sports Exerc. 2010, 42, 781-790. [CrossRef] [PubMed]

25. Stastny, P.; Tufano, J.; Kregl, J.; Petr, M.; Blazek, D.; Steffl, M.; Roczniok, R.; Fiala, M.; Golas, A.; Zmijewski, P. The Role of Visual Feedback on Power Output During Intermittent Wingate Testing in Ice Hockey Players. Sports 2018, 6, 32. [CrossRef] [PubMed]

26. Duchateau, J.; Baudry, S. Maximal discharge rate of motor units determines the maximal rate of force development during ballistic contractions in human. Front. Hum. Neurosci. 2014, 8, 1-3. [CrossRef] [PubMed] 
27. Dirnberger, J.; Wiesinger, H.P.; Wiemer, N.; Kösters, A.; Müller, E. Explosive strength of the knee extensors: The influence of criterion trial detection methodology on measurement reproducibility. J. Hum. Kinet. 2016, 50, 15-25. [CrossRef]

28. Koo, T.K.; Li, M.Y. A Guideline of selecting and reporting intraclasscorrelation coefficients for reliability research. J. Chiropr. Med. 2016, 15, 155-163. [CrossRef]

29. Atkinson, G.; Nevill, A. Statistical methods for assssing measurement Error (reliability) in variables relevant to sports medicine. Sports Med. 1998, 26, 217-238. [CrossRef]

30. Bishop, C.; Turner, A.; Read, P. Effects of inter-limb asymmetries on physical and sports performance: A systematic review. J. Sports Sci. 2018, 36, 1135-1144. [CrossRef]

31. Lakens, D. Calculating and reporting effect sizes to facilitate cumulative science: A practical primer for t-tests and ANOVAs. Front. Psychol. 2013, 4, 863. [CrossRef]

32. Kiff, A.B. Effect of Focus of Attention on Rate of Torque Development in the Knee Extensors; Oregon State University: Corvallis, OR, USA, 2017.

(C) 2020 by the authors. Licensee MDPI, Basel, Switzerland. This article is an open access article distributed under the terms and conditions of the Creative Commons Attribution (CC BY) license (http://creativecommons.org/licenses/by/4.0/). 